\title{
Personality Traits as Predictor of Emotional Intelligence among the University Teachers as Advisors
}

\author{
Nawal G. Alghamdi, ${ }^{1}$ Muhammad Aslam, ${ }^{2}$ and Khushnoor Khan ${ }^{2}$ \\ ${ }^{1}$ Department of Psychology, King Abdulaziz University, Jeddah 21551, Saudi Arabia \\ ${ }^{2}$ Department of Statistics, Faculty of Science, King Abdulaziz University, Jeddah 21551, Saudi Arabia \\ Correspondence should be addressed to Muhammad Aslam; aslam_ravian@hotmail.com
}

Received 20 February 2017; Accepted 30 March 2017; Published 14 May 2017

Academic Editor: Gwo-Jen Hwang

Copyright ( 2017 Nawal G. Alghamdi et al. This is an open access article distributed under the Creative Commons Attribution License, which permits unrestricted use, distribution, and reproduction in any medium, provided the original work is properly cited.

\begin{abstract}
The focus of the present study was to investigate personality traits as the predictor of emotional intelligence (EI) among the university teachers working as student advisors. A sample of the study comprised 100 student advisors $($ male $=50$; female $=50)$. The age range of the sample was 21-40 years. Schutte Emotional Intelligence Scale (SEIS) and Big Five Inventory (BFI) were used to measure emotional intelligence (EI) and personality traits. For the statistical analysis of the data, $T$-test and regression analysis were computed. The findings revealed that three personality traits, extraversion, agreeableness, and openness to experience, emerged as significant predictors of EI. The findings also revealed that conscientiousness and neuroticism have no impact on EI. T-tests indicated that there are no gender differences in EI. Considering the implication of personality traits on EI among university teachers/student advisors, the current research may assist in augmenting the organizational behavior in general and boost the productivity in particular which are both essential ingredients for the deliverance of services to all the stakeholders linked with the educational system in Saudi Arabia.
\end{abstract}

\section{Introduction}

Ministry of Education in Saudi Arabia felt a need for career decision-making and conflict resolution of students in academia. For addressing the said problem, the General Administration of Guidance and Counseling initiated counseling and advisory service programs at the educational institutes through teachers, who were not as professionally equipped as they should have been to execute the role of advisory and counseling. The underlying idea was to commence the program and let nonprofessional advisors who are working as teachers keep on rendering advisory services till the time fully trained professional advisors are available. However, teachers while acting as advisors in educational institutes faced some problems and obstacles that influenced their performance and mental wellbeing. One foremost factor leading to this problem was the unclear role of advisors in an educational institution. The advisory and counseling role is quite ambiguous for administrators, students, and even the advisors themselves [1]. Counselors and advisors at schools, colleges, and universities require being upbeat to find effective approaches to establishing superior-quality generation for individual and national progress. Advisors and counselors at educational institutes play a vital role in the nurturance and development of youth with quality characteristics. In today's challenging world, it is a crucial responsibility of the teachers, educators, student advisors, and counselors to mold a generation which possesses healthy and enriched personality traits, a higher level of intelligence, a higher level of emotional intelligence, good coping abilities, and higher achievement orientation. For inculcating such attributes in the youth, emotional intelligence coupled with an enriched personality is recognized as core competencies for the advisors and counselors for providing effective counseling services. Present research focuses on the investigation of personality traits as predictors of EI among the university teachers serving as student advisors. 


\section{Literature Review}

Emotion is an outcome of the interaction flanked by the physiological stimulation and evaluation of the situation. As soon as a physiological stimulation is experienced, it is the stimulus or situation or events in the surroundings of a person that spell out which emotions will be experienced by the person. Emotions and moods are a natural part of an individual's makeup. One cannot divorce emotions from the workplace because you cannot divorce emotions from people [2]. Three aspects of EI as proposed by Salovey and Mayer [3] are (a) appraisal and expression of emotion, (b) regulation of emotion, and (c) utilization of emotion.

EI is the capability to have a precise insight of appraise and articulate one's own and others' emotions and to retrieve and create feelings as soon as they facilitate thinking [4], as well as controlling and employing emotions in problem resolution [5]. EI is the ability for acknowledging one's feelings and emotions and also those of others, for stirring oneself, and for regulating emotions in a good way in oneself and other people [6]. The differing names given to emotional intelligence are part of the reason that it has been difficult for researchers to agree on an all-encompassing definition [7]. A study [8] looked into the six qualities of 11 American presidents, and the findings of the study highlighted that the key quality that differentiated the successful from the unsuccessful president was EI. These emotional abilities are distinctive from, but harmonizing to, the cognitive intelligence indicated by the measurement of IQ. Currently, EI is characterized by some researchers as an ability, involving the cognitive processing of emotional information, which is accordingly most appropriately measured by performance tests [9].

In short, it can be stated that EI is the ability of a person to detect and to handle emotional cues and information and respond accordingly. The concept of emotional intelligence has inspired numerous school-based programs of social and emotional learning, as well as management training programs [10]. Emotional intelligence is expected to be linked to a range of theoretically interesting outcomes [9]. EI is considered to be a prerequisite for the teachers working as student advisors as they are required not only to deal with the problems of the student but also to effectively tackle the emotions of students who are in problem. Teachers should serve as role models because their effective advisory service helps students to acquire ways of regulating their emotions. Hence, a strong need is felt for the development of the emotional and social growth in students, right from the elementary level to the highest echelons of learning, that is, universities. Understanding, managing, and employing emotions are required to build up a strong personality. Personality traits may be, in part, genetically based and fairly stable over time. However, adult personality is not rigidly determined from birth, and there is room for change [10]. For the skillful management of emotions, it is required to have an understanding of emotions and awareness of the individual differences. These individual differences are observable in the characteristics and behaviors that are possessed by an individual and that can be expressed as personality [11]. Unlike cognitive ability, EI is most reliably assessed via self-report inventories, rather than objective performance tests. Therefore, the label "trait EI" has been put forward to reflect its taxonomic position within the realm of personality [12]. There existed an interdependent relationship between personality traits and EI. Research indicates that personality traits have an effect on the development of the emotional quotient of an individual, and emotional quotient has an influence on the application and development of the personality of the individual [13].

Literature reveals an established evidence for a strong association between EI and various personality traits [14]. Dawda and Hart [15] reported a significant relationship between EI and all Big Five personality factors. Day et al. [16] reported in their study that there exists a high correlation between EI and extraversion and conscientiousness. A study conducted by Avsec et al. [17] revealed that EI is a predictor of the Big Five. Conscientiousness makes the most contribution in EI whereas neuroticism contributes the least. Extraversion, openness, and agreeableness also predict emotional intelligence. For further references, see [18-21] and Zembylas [22].

Gender differences concerning EI depend on the kind of assessment tool used, self-report or performance measures. The findings of studies that have used self-report measures have been very dissimilar. Lack of uniformity in the results could be due to sample's sociodemographic characteristics or the kind of toll used. Hence, the present study also tries to look into the gender difference viz-à-viz EI.

\section{Method}

\subsection{Objectives}

(i) To study the impact of five personality traits on EI.

(ii) To study the gender differences between personality traits and EI.

\subsection{Hypotheses}

(H1) Extraversion has a significant impact on EI.

(H2) Agreeableness has a significant impact on EI.

(H3) Conscientiousness has a significant impact on EI.

(H4) Neuroticism does not have a significant impact on EI.

(H5) Openness to experience has a significant impact on EI.

(H6) Significant gender differences exist between personality traits and EI.

3.3. Sample. A sample of the study consisted of 100 teachers rendering services as student advisors (male $=50$; female $=$ 50) working in KAU from nine departments: Computer and Information Technology, Environmental Engineering, Applied Psychology, Geology, Biochemistry, Physics, Biology, English, and Mathematics. The age range of the participants was $21-40$ years. The sampling technique applied for drawing out the sample was convenience sampling. 


\subsection{Instruments}

3.4.1. Demographic Sheet. A demographic sheet measuring biographic data of the participants was used for the present study. It measured variables like age, gender, and education.

3.4.2. The Schutte Self-Report Emotional Intelligence Test (SSEIT). This scale consists of 33 items to measure EI. Schutte and his associates developed the scale in 1998 [23]. Items of the test relate to the three aspects of emotional intelligence: (a) appraisal and expression of emotion, (b) regulation of emotion, and (c) utilization of emotion. It has been developed on a 5-point Likert scale format where 1 indicates strongly disagree and 5 indicates strongly agree. Items 5, 28, and 33 are reverse-scored. The scale has sound psychometric properties, Cronbach's alpha reported to be 0.90 , and test-retest reliability to be 0.78 .

3.4.3. Big Five Inventory (BFI). It is a 44-item questionnaire developed by Benet-Martinez and John in 1998 [24], to measure the prototypical personality traits comprising the Big Five dimensions. The dimension of extraversion consists of eight items, out of which three are reverse-scored. The dimensions of agreeableness and conscientiousness have nine items each, out of which 4 are reverse-scored for each. Neuroticism consists of 8 items with 3 reverse-scored items and 10 items are for openness to experience with 2 reversescored items. The items are rated on a 5-point Likert scale where 1 indicates strongly disagree and 5 indicates strongly agree. BFI has reflected substantial internal consistency in researches varying from .77 to .81 .

3.5. Procedure. The sample size was determined using GPower software with small effect size of $\rho=0.3$, and power of the test $=0.80$ and $\alpha=0.01$; the sample size calculated was approximately 105; the relevant graph is attached in the Appendix. A convenient sample of 100 teachers who were working as student advisors or counselors in different departments of the university was approached. The respondents have explained the purpose of the study and their consent was taken for the study participation. They were affirmed regarding the confidentiality of their responses and were affirmed that the information sought from them will only be utilized for research purposes. They were handed over the study questionnaire which consisted of demographic information, Big Five Inventory, and Schutte Emotion Regulation Questionnaire. After the completion of study questionnaire, each participant was thanked for their cooperation and participation. The study data was analyzed using SPSS version 21. Cross-sectional studies perform comparisons at a single point in time, whereas longitudinal studies make comparisons over time. The research question determines which approach best suits the study. Study design depends considerably on the nature of the research question. In other words, knowing what kind of information the study should collect is a first step in learning how the study will be carried out (also known as a methodology). Both the cross-sectional and the longitudinal studies are observation studies. This means that a researcher
TABLE 1: Frequency and percentage of the sample regarding demographics $(N=100)$.

\begin{tabular}{lll}
\hline & $f$ & $\%$ \\
\hline Gender & & \\
Male & 50 & 50.0 \\
Female & 50 & 50.0 \\
Age & & \\
$21-30$ & 40 & 40.0 \\
$31-40$ & 60 & 60.0 \\
Qualification & & \\
BS & 10 & 10.0 \\
Ph.D & 53 & 53.0 \\
Masters & 37 & 37.0 \\
\hline
\end{tabular}

records information about subjects without manipulating the study environment. Hence, two points emerge out of the above discussion:

(1) A number of contacts with the subjects.

(2) Noninterference of the researcher.

In the current study, the researchers simply measure the impact of the personality traits on the emotional intelligence. In short, the research question is "how emotional intelligence is affected by various personality traits." To address this research question, the researcher needs to collect information from the respondents using a questionnaire having multiple questions which look into the personality traits and emotional intelligence of the respondents. The number of contacts of the researcher with the respondents is only one; therefore, this is study warrants a cross-sectional study design and not a longitudinal study design.

Cross-sectional designs are useful in obtaining an overall "picture" as it stands at the time of the study. They are designed to study some phenomenon by taking a cross section of it at one time (see Babbie (1989) for more details). The gender classification is shown in Table 1.

\section{Results}

Table 2 shows that Cronbach's Alpha for Schutte Emotional Intelligence Scale (SEIS) and Big Five Inventory (BFI) is 0.77 and 0.72 which shows that the items have high internal consistency and are suitable for the study population.

Table 3 exhibits that extraversion positively predicts emotional intelligence. The values of $\Delta R^{2}$ of .17 indicate that a $17 \%$ variance in the emotional intelligence is attributed by the predictor extraversion with $F=21.49$ and $p<.01$. Thus, extraversion has a positive impact on $\mathrm{EI}(\beta=.42, p<.01)$.

Table 4 shows that agreeableness positively predicts emotional intelligence. The values of $\Delta R^{2}$ of .08 indicate an $8 \%$ variance in the emotional intelligence by the predictor which is agreeableness with $F=9.94$ and $p<.01$. Thus, agreeableness has a positive impact on emotional intelligence $(\beta=.30, p<.01)$.

Table 5 shows that conscientiousness has no significant impact on emotional intelligence. The values of $\Delta R^{2}$ of .000 
TABLE 2: Reliability analysis of Schutte Emotional Intelligence Scale (SEIS) and Big Five Inventory (BFI) $(N=100)$.

\begin{tabular}{lcc}
\hline Scale & Number of items & Cronbach's Alpha \\
\hline EI & 33 & 0.77 \\
BFI & 44 & 0.72 \\
\hline
\end{tabular}

Note. SEIS: Schutte Emotional Intelligence Scale and BFI: Big Five Inventory.

TABLE 3: Linear regression analysis indicating extraversion as the predictor of EI $(N=100)$.

\begin{tabular}{lccccc}
\hline Model & $b$ & SE & $\beta$ & $t$ & $p$ \\
\hline Constant & 84.52 & 7.62 & & 11.09 & .000 \\
Extraversion & 1.49 & .32 & .42 & 4.63 & .000 \\
$R^{2}=.18$ & & & & & \\
$\Delta R^{2}=.17$ & & & & & \\
\hline
\end{tabular}

TABLE 4: Linear regression analysis indicating agreeableness as the predictor of EI $(N=100)$.

\begin{tabular}{lccccc}
\hline Model & $b$ & SE & $\beta$ & $t$ & $p$ \\
\hline Constant & 78.93 & 12.88 & & 6.12 & .000 \\
Agreeableness & 1.27 & .40 & .30 & 3.15 & .002 \\
$R^{2}=.09$ & & & & & \\
$\Delta R^{2}=.08$ & & & & & \\
\hline
\end{tabular}

TABLE 5: Linear regression analysis indicating conscientiousness as the predictor of EI $(N=100)$.

\begin{tabular}{lccccc}
\hline Model & $b$ & SE & $\beta$ & $t$ & $p$ \\
\hline Constant & 105.36 & 11.35 & & 9.28 & .000 \\
Conscientiousness & .46 & .37 & .12 & 1.23 & .219 \\
$R^{2}=.01$ & & & & & \\
$\Delta R^{2}=.00$ & & & & & \\
\hline
\end{tabular}

indicate a $0 \%$ or no variance in the emotional intelligence by conscientiousness $(F=1.53$ and $\beta=.30, p>.05)$.

Table 6 shows that neuroticism has no significant impact on emotional intelligence. The values of $\Delta R^{2}$ of .00 indicate a $0 \%$ or no variance in the emotional intelligence by neuroti$\operatorname{cism}(F=.35$ and $\beta=.60, p>.05)$.

Table 7 shows that openness to experience positively predicts emotional intelligence. The values of $\Delta R^{2}$ of .10 indicate a $10 \%$ variance in the emotional intelligence by openness to experience $(F=12.50, p<.01)$. Thus, openness to experience has a positive impact on emotional intelligence $(\beta=.33, p<.01)$.

Table 8 reveals that there exists no gender difference regarding emotion intelligence among the teachers serving as student advisors.

Table 9 summarized the six hypotheses and their results.

\section{Discussion}

Since the last decade, the educational sector in Saudi Arabia has given a profound recognition to the significance of career guidance and counseling programs. It indicates that
TABLE 6: Linear regression analysis indicating neuroticism as the predictor of EI $(N=100)$.

\begin{tabular}{lccccc}
\hline Model & $b$ & SE & $\beta$ & $t$ & $p$ \\
\hline Constant & 112.82 & 10.99 & & 10.26 & .000 \\
Neuroticism & .24 & .40 & .06 & .59 & .554 \\
$R^{2}=.00$ & & & & & \\
$\Delta R^{2}=.00$ & & & & & \\
\hline
\end{tabular}

TABLE 7: Linear regression analysis indicating openness to experience as the predictor of EI $(N=100)$.

\begin{tabular}{lccccc}
\hline Model & $b$ & SE & $\beta$ & $t$ & $p$ \\
\hline Constant & 85.83 & 9.56 & & 8.97 & .000 \\
Openness to experience & .94 & .26 & .33 & 3.53 & .001 \\
$R^{2}=.11$ & & & & & \\
$\Delta R^{2}=.10$ & & & & & \\
\hline
\end{tabular}

educators in Saudi Arabia are very well aware of the needs of advisory, guidance, and counseling of the students. They are for implementing institutional counseling programs led by trained counselors [25]. But at present, the teachers who are rendering such services have not undergone any professional training in advisory services or counseling. In Saudi Arabia, the main agenda regarding youth development is to generate youth with well-built personality and to achieve this teacher advisors and most specifically counselors can play a significant role. Student advisor or counselor is a vital person having the responsibility of helping the students to achieve academic advances as well as psychological health. Corey [26] stated that one of the most significant instruments to be employed in student counseling is the counselor himself/herself. Literature reveals that the personal attributes of the advisor or counselor are very influential and important factors in determining the usefulness of counseling services $[27,28]$. The main focus of the university education system is aimed at enhancing the academic performance of students which in turn is interlinked with personality traits of quality teachers, advisors, and counselors at the university. Thus, quality teachers and advisors also tend to enhance the overall performance of the institutes as stated by [29].

The present study investigated the five personality traits as predictors of EI. The findings revealed that three of the personality traits, extraversion, agreeableness, and openness to experience, emerged as significant predictors of emotional intelligence. Findings also revealed that conscientiousness and neuroticism have no impact on EI. The findings are consistent with the literature $[17,30]$. A study conducted by Iruloh and Ukaegbu [31] indicated that the qualified contributions are made by personality traits of agreeableness and extraversion in higher EI of secondary school teachers. The authors also revealed that conscientiousness, openness, and neuroticism did not contribute to emotional intelligence. A study conducted by Van Rooy and Viswesvaran [7] also indicated that EI and personality appear to be more highly correlated as researchers would prefer. Indeed, three of the Big Five factors of personality had correlations with EI more 
TABLE 8: Mean, standard deviation, and $t$-values on procrastination and self-regulation $(N=100)$.

\begin{tabular}{|c|c|c|c|c|c|c|c|c|c|}
\hline & \multirow{2}{*}{ Gender } & \multirow{2}{*}{$N$} & \multirow{2}{*}{$M$} & \multirow{2}{*}{ SD } & \multirow{2}{*}{$\mathrm{df}$} & \multirow{2}{*}{$t$} & \multirow{2}{*}{$p$} & \multicolumn{2}{|c|}{$95 \%$ confidence interval } \\
\hline & & & & & & & & LL & UL \\
\hline \multirow{2}{*}{ EI } & Male & 50 & 122.10 & 15.26 & \multirow{2}{*}{98} & \multirow{2}{*}{1.90} & \multirow{2}{*}{.06} & -.25 & 11.49 \\
\hline & Female & 50 & 116.48 & 14.30 & & & & -.25 & 11.49 \\
\hline
\end{tabular}

Note. Emotional intelligence: EI.

TABLE 9: Summary of hypotheses.

\begin{tabular}{lrr}
\hline Serial number & Hypotheses & Outcomes \\
\hline 1 & Extraversion has a significant impact on EI & Significant \\
2 & Agreeableness has a significant impact on EI & Significant \\
3 & Conscientiousness has a significant impact on EI. & Nonsignificant \\
4 & Neuroticism does not have a significant impact on EI & Nonsignificant \\
5 & Openness to experience has a significant impact on EI & Significant \\
6 & Significant gender differences exist between personality & Nonsignificant \\
\hline
\end{tabular}

than .31; the weakest correlation was .23 with agreeableness and openness to experience. There was a general pattern of low correlations between scores on an emotional intelligence test, on the one hand, and personality traits on the other hand [10].

Findings also indicated that there are no gender differences about EI. The findings are supported by the similar results by a study "Women's Leadership Edge: Global Research on Emotional Intelligence, Gender, and Job Level" conducted in 2012 [32].

Considering the implications of personality traits towards EI among university teachers/student advisors or counselors, the current research may assist in augmenting organizational behavior in general and boost productivity in particular which are both most premium ingredients for the deliverance of quality service to the stakeholders connected with the educational system in Saudi Arabia. It is further suggested that personality development programs can periodically be initiated for personality enhancement and emotional skills of the teachers and students simultaneously. It will help the university administration to achieve an enriched environment for learning, academic improvements, and developing quality personality characteristics. Considering the implication of personality traits on EI, the current research may assist in augmenting the organizational behavior in general and boosting productivity in particular which are both essential ingredients for the deliverance of services to all the stakeholders linked with the educational system.

The present design can be extended for a longitudinal cross-analysis as future research.

\section{Appendix}

See Figure 1.

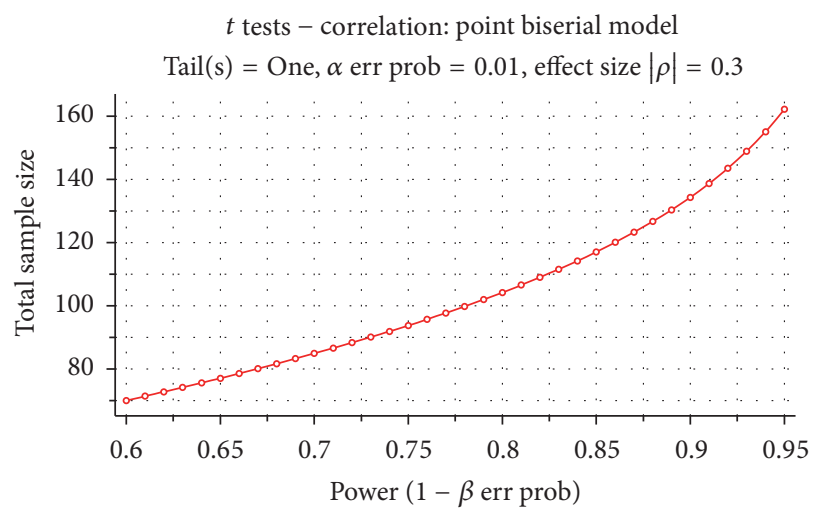

Figure 1: Sample size determination.

\section{Conflicts of Interest}

The authors declare that they have no conflicts of interest.

\section{Acknowledgments}

This article was funded by the Deanship of Scientific Research (DSR), King Abdulaziz University, Jeddah. The authors, therefore, acknowledge with thanks DSR technical and financial support.

\section{References}

[1] P. O. Paisley and H. G. McMahon, "School Counseling for the twenty-first century: Challenges and opportunities," Professional School Counseling, vol. 5, pp. 106-115, 2001.

[2] S. Nelson, Emotions at the Work place, Nation's Business, 1996.

[3] P. Salovey and J. D. Mayer, Emotional Intelligence, Baywood Publishing Co, 1990. 
[4] J. D. Mayer, P. Salovey, and D. R. Caruso, "Emotional intelligence as zeitgeist, as personality, and as a mental ability: The handbook of emotional intelligence," Prentice Hall, NJ, USA, 2000.

[5] C. Saarni, The Handbook of Emotional Intelligence Emotional Competence: A Developmental Perspective, Waveland Press, 2000.

[6] D. Goleman, Working with Emotional Intelligence, Bantam Books, NY, USA, 1998.

[7] D. L. Van Rooy and C. Viswesvaran, "Emotional intelligence: A meta-analytic investigation of predictive validity and nomological net," Journal of Vocational Behavior, vol. 65, no. 1, pp. 71-95, 2004.

[8] F. I. Greenstein, The Presidential Difference: Leadership Style from FDR to Clinton, Princeton University Press, 2001.

[9] E. J. Austin, D. H. Saklofske, and V. Egan, "Personality, wellbeing and health correlates of trait emotional intelligence," Personality and Individual Differences, vol. 38, no. 3, pp. 547558, 2005.

[10] P. N. Lopes, P. Salovey, and R. Straus, "Emotional intelligence, personality, and the perceived quality of social relationships," Personality and Individual Differences, vol. 35, no. 3, pp. 641-658, 2003.

[11] M. Maccoby, "To win the respect of followers, leaders need personality intelligence," Ivey Business Journal Online, vol. 72, no. 3, p. 1, 2008.

[12] T. Chamorro-Premuzic, E. Bennett, and A. Furnham, "The happy personality: mediational role of trait emotional intelligence," Personality and Individual Differences, vol. 42, no. 8, pp. 1633-1639, 2007.

[13] A. Das, "Effects of personality on emotion intelligence between professional and nonprofessional students: some exploratory evidence," Asia Journal of Management Research, vol. 1, no. 2, pp. 746-758, 2011.

[14] J. D. Mayer, "Emotional intelligence: popular or scientific psychology," APA Monitor Online, vol. 30, no. 8, 1999, Retrieved from http://www.apa.org/monitor/sept99/sp.html.

[15] D. Dawda and S. D. Hart, "Assessing emotional intelligence: reliability and validity of the Bar-On Emotional Quotient Inventory (EQ-i) in university students," Personality and Individual Differences, vol. 28, no. 4, pp. 797-812, 2000.

[16] A. L. Day, D. L. Therrien, and S. A. Carroll, "Predicting psychological health: assessing the incremental validity of emotional intelligence beyond personality, type a behaviour, and daily hassles," European Journal of Personality, vol. 19, no. 6, pp. 519536, 2005.

[17] A. Avsec, V. Takšic, T. Mohoric, and V. Takšic, “The relationship of trait emotional intelligence with the big five in croatian and slovene university student samples," Psihološka obzorja/Horizons of Psychology, vol. 18, no. 3, pp. 99-110, 2009.

[18] V. A. Bastian, N. R. Burns, and T. Nettelbeck, "Emotional intelligence predicts life skills, but not as well as personality and cognitive abilities," Personality and Individual Differences, vol. 39, no. 6, pp. 1135-1145, 2005.

[19] G. Matthews, A. K. Emo, G. Funke et al., "Emotional intelligence, personality, and task-induced stress," Journal of Experimental Psychology: Applied, vol. 12, no. 2, p. 96, 2006.

[20] M. J. Schulte, M. J. Ree, and T. R. Carretta, "Emotional intelligence: not much more than g and personality," Personality and Individual Differences, vol. 37, no. 5, pp. 1059-1068, 2004.
[21] R. D. Shaffer and M. A. Shaffer, "Emotional intelligence abilities, personality and workplace performance. in academy of management proceedings," Academy of Management, vol. 1, pp. M1M6, 2005.

[22] M. Zembylas, "Wilful ignorance and the emotional regime of schools," British Journal of Educational Studies, pp. 1-17, 2017.

[23] N. S. Schutte, J. M. Malouff, L. E. Hall, D. J. Haggerty, J. T. Cooper, C. J. Golden et al., "Development and validation of a measure of emotional intelligence," Personality and Individual Differences, vol. 25, pp. 167-177, 1998.

[24] V. Benet-Martinez and O. P. John, "Los Cinco Grandes across cultures and ethnic groups: Multitrait multimethod analyses of the Big Five in Spanish and English," Journal of Personality and Social Psychology, vol. 75, pp. 729-750, 1998.

[25] B. Al-Sayed, Training needs of teachers in mainstream primary schools in Saudi Arabia in relation to pupils with SEN [Ph.D. thesis], University of Hull, Hull, UK, 2002.

[26] G. Corey, "Theory and practice of counseling \& psychotherapy," Thomson: Brooks/Cole Publishing Company, Ke- 7 edition, 2005.

[27] L. Brammer, "Teaching personal problem solving to adults," Journal of Cognitive Psychotherapy, vol. 4, pp. 267-280, 1993.

[28] E. Karen and M. Garret, "A measure of counselor competency," Counsellor Education \& Supervision, vol. 43, pp. 120-133, 2003.

[29] L. A. Weinberger, An examination of the relationship between emotional intelligence and leadership style, The University of Minnesota, 2004.

[30] H. K. Andi, "Relationships between emotional intelligence and 'The Big Five In Youths,' Malaysian Journal of Youth Studies, vol. 7, pp. 125-135, 2012.

[31] B. R. N. Iruloh and H. M. Ukaegbu, "Big five personality traits as predictors of emotional intelligence of secondary school teachers in Rivers State of Nigeria," European Journal of Psychological Research, vol. 2, no. 2, pp. 52-59, 2015.

[32] "Women's Leadership Edge: Global Research on Emotional Intelligence, Gender, and Job Level," Six Seconds, September 2012, http://www.6seconds.org/2012/09/11/research-emotionalintelligence-gender-career/. 


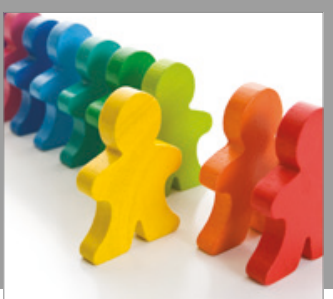

Autism

Research and Treatment
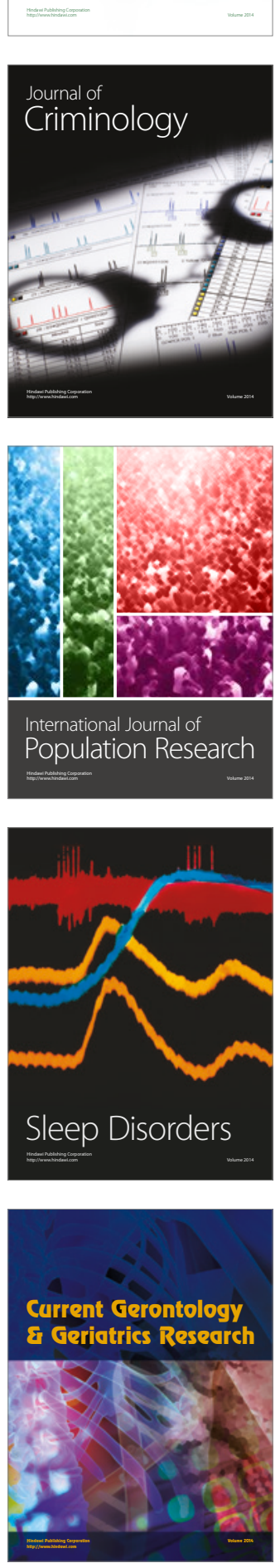

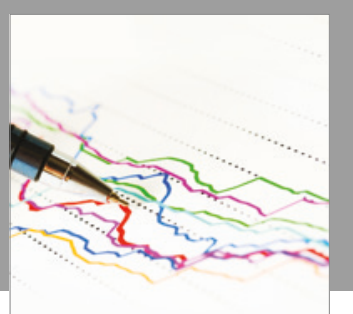

Economics

Research International

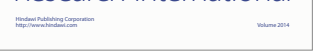

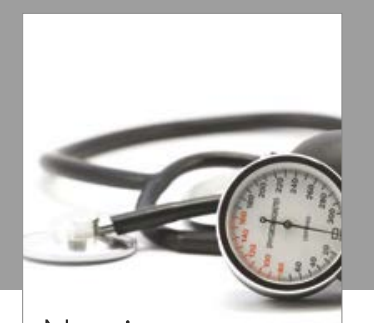

Nursing

Research and Practice

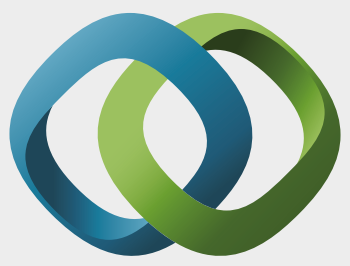

\section{Hindawi}

Submit your manuscripts at

https://www.hindawi.com
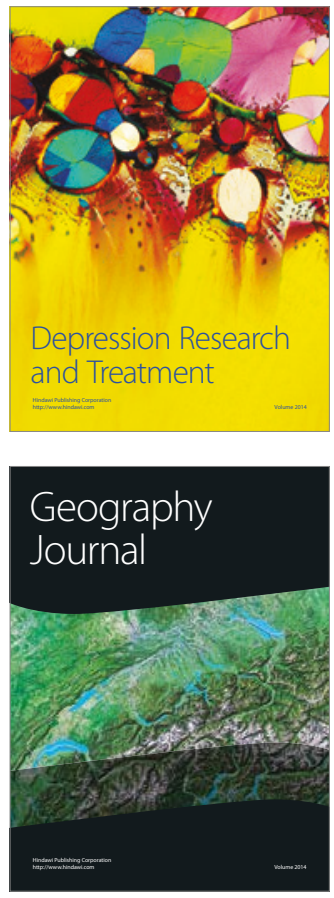
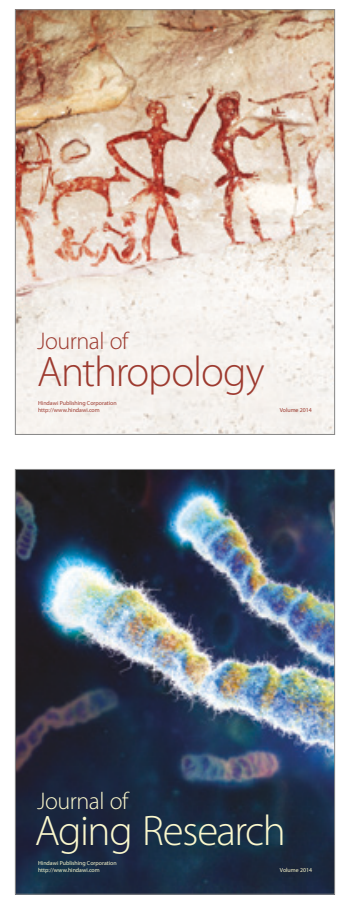
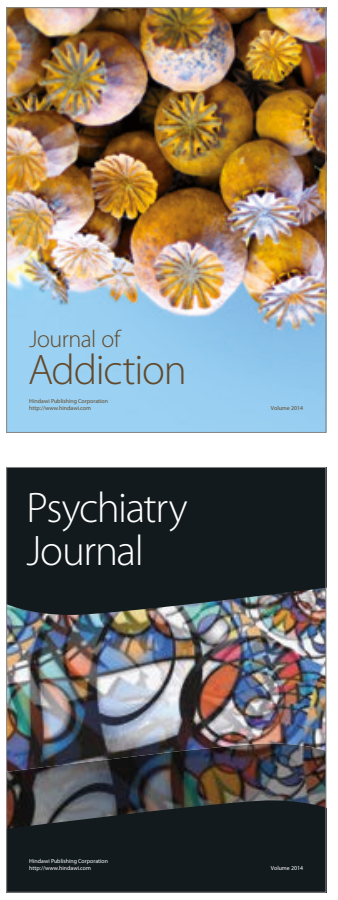

Child Development

Research

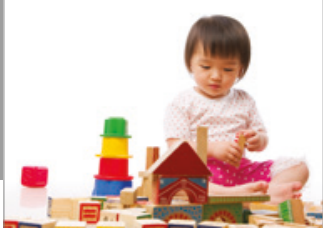

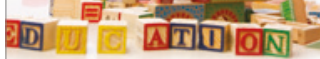
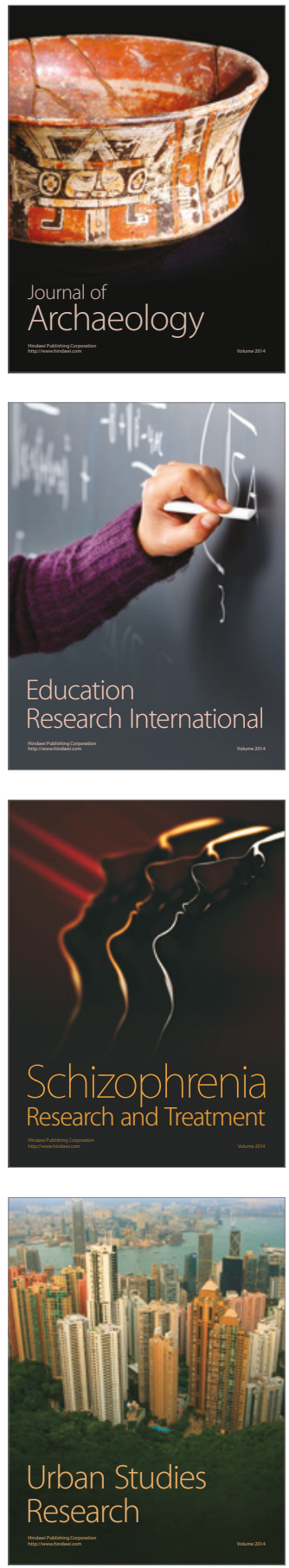